\title{
PENGARUH MANAJEMEN PENGETAHUAN, KOMPETENSI, DAN PENGALAMAN KERJA DENGAN MOTIVASI KERJA SEBAGAI MEDIASI TERHADAP KINERJA PEGAWAI DI JAKARTA UTARA
}

\begin{abstract}
Nicholas Tan dan M. Tony Nawawi
Program studi S1 Manajemen Fakultas Ekonomi dan Bisnis Universtas Tarumanagara, Jakarta

Nicholas.115170228@stu.untar.ac.id

tonyn@fe.untar.ac.id

Abstract: This study aims to determine and predict the effect of Knowledge Management, Competence, Work Experience and Work Motivation as a mediation on Employee Performance in North Jakarta. The population in this study were 57 employees who worked in the north Jakarta area. In sampling, the researcher uses non-probability sampling where members or members of the population do not have the same opportunity to be selected or where the sampling or selection of samples is not based on the law of probability and there is no equal opportunity for members to remain selected. Then the researcher will use purposive sampling because the researcher has found adequate information related to the research so that using this sampling technique will help researchers to get a good and correct sample. In testing the data, researchers used SmartPLS 3. The results showed that Knowledge Management and Competence had a positive effect on employee performance, work experience did not have a positive effect on employee performance in north Jakarta, the last one that work motivation also did not have a positive effect on connecting the independent variables to the dependent variable. namely Employee Performance.
\end{abstract}

Keywords: Knowledge Management, Competence, Work Experience, Work Motivation, Employee Performance, Employee Performance.

Abstrak: Penelitian ini bertujuan untuk mengetahui dan memprediksi pengaruh Manajemen Pengetahuan, Kompetensi, Pengalaman Kerja serta Motivasi Kerja sebagai mediasi terhadap Kinerja Pegawai di Jakarta utara. Populasi dalam penelitian ini sebanyak 57 pegawai yang bekerja di daerah Jakarta utara. Dalam pengambilan sampel, peneliti menggunakan non-probability sampling dimana anggota atau member dari populasi tidak memiliki kesempatan yang sama untuk terpilih atau dimana pengambilan atau pemilihan sample tidak didasarkan pada hukum probabilitas dan tidak adanya peluang yang sama bagi anggota untuk tetap dipilih. Lalu peneliti akan menggunakan purposive sampling dikarenakan peneliti telah menemukan informasi yang memadai terkait penelitian sehingga dengan menggunakan teknik sampling ini akan membantu peneliti untuk mendapatkan sample yang baik dan benar. Dalam pengujian data peneliti menggunakan SmartPLS 3. Hasil penelitian menunjukkan bahwa Manajemen Pengetahuan, dan Kompetensi berpengaruh positif terhadap Kinerja Pegawai, Pengalaman kerja tidak berpengaruh positif terhadap Kinerja Pegawai di Jakarta utara yang terakhir bahwa Motivasi kerja juga tidak berpengaruh positif dalam menhubungkan variabel independen terhadap variabel dependen yaitu Kinerja Pegawai.

Kata Kunci: Manajemen Pengetahuan, Kompetensi, Pengalaman Kerja, Motivasi Kerja, Kinerja Pegawai, Kinerja Karyawan. 


\section{LATAR BELAKANG}

Kondisi ekonomi nasional yang saat ini yang bisa dikatakan menurun terus setiap harinya dapat disebabkan oleh banyaknya angka kemiskinan di dalam suatu negara hal ini menyebabkan banyaknya orang yang tidak bekerja tetap/pengangguran yang membuat kehidupan mereka semakin terpuruk oleh keadaan ekonomi saat ini, apalagi terdapat pandemic Covid-19 yang membuat kondisi ekonomi nasional semakin menurun dan terdapat batasan untuk bekerja setiap harinya, maka dari itu setiap perusahaan harus bisa memberikan kinerja terbaik mereka guna meningkatkan kondisi ekonomi nasional. tidak hanya di Indonesia saja karena terjadinya pandemic penurunan ekonomi terjadi di hampir seluruh penjuru dunia Akibatnya, pertumbuhan ekonomi semua negara kembali tertekan. Pertumbuhan beberapa negara mengalami kontraksi, dan sebagian lainnya masih tumbuh positif meskipun jauh dibawah pertumbuhan normal. Perekonomian Tiongkok berbalik terkontraksi hingga 6,8 persen. Jepang terkontraksi semakin dalam sebesar 3,4 persen. Sementara itu, Amerika Serikat masih tumbuh positif sebesar 0,3 persen. Pertumbuhan ekonomi Indonesia sendiri tertekan menjadi 2,97 persen.

Adanya manajemen pengetahuan akan berdampak besar terhadap kinerja apabila seorang pegawai sudah ahli dalam bidangnya dan memiliki pemikiran yang luas dan dapat berpikir secara kritis dan realistis, dalam jurnal Ridha Choirun Nisa, Armstrong (2008:149) mengartikan manajemen pengetahuan sebagai setiap proses atau praktek membuat, memperoleh, menangkap, berbagi, dan menggunakan pengetahuan untuk meningkatkan pembelajaran dan kinerja organisasi,

Dalam jurnal Dhermawan, N. B., Menurut (Ruky ,2006) kompetensi adalah karakteristik dasar seorang (individu) yang mempengaruhi cara berpikir dan bertindak, membuat generalisasi terhadap segala situasi yang dihadapi serta bertahan cukup lama dalam diri manusia.

- Menurut Syukur (2001:74) menyatakan bahwa Pengalaman kerja adalah lamanya seseorang melaksanakan frekuensi dan jenis tugas sesuai dengan kemampuannya. Hal ini sejalan dengan teori yang dinyatakan Robbins dan Timothy (2008) bahwa pengalaman kerja didasarkan pada pengetahuan dan keterampilan yang dimiliki karyawan, Dimensi pengalaman kerja yang digunakan dalam penelitian ini mengacu pada pendapat yang disampaikan Foster (2001) dalam Luh Aristarini bahwa pengukuran pengalaman kerja dapat dilihat dari lama waktu atau masa kerja, tingkat pengetahuan dan keterampilan yang dimiliki, serta jenis pekerjaan.

Pada jurnal Luh Aristarini dkk, Vancevich dkk (2006) dan John (2007) menyatakan bahwa motivasi kerja didasarkan pada kesediaan karyawan untuk bekerja dengan baik. Dimensi motivasi kerja yang digunakan dalam penelitian ini mengacu pada pendapat yang disampaikan Ivancevich dkk (2006) yaitu tujuan karyawan bekerja dan perilaku karyawan.

Menurut Taurisa dan Ratnawati (2012) dalam Stella Karunia Avera dan M. Tony Nawawi kinerja karyawan merupakan hasil kerja secara kualitas maupun kuantitas yang dicapai oleh seseorang dalam melaksanaka tugas yang diberikan kepadanya sesuai dengan standar atau kriteria yang telah ditetapkan. 


\section{LANDASAN TEORI}

\section{Keterkaitan antara variabel}

\section{Pengaruh manajemen pengetahuan dengan kinerja pegawai.}

Aplikasi pengetahuan melibatkan penyimpanan, pengambilan, aplikasi, dan berbagi. Davenport \& Klahr (1998) mencatat bahwa aplikasi pengetahuan yang efektif telah membantu perusahaan untuk meningkatkan efisiensi dan mengurangi biaya.

\section{Pengaruh kompetensi dengan kinerja pegawai.}

Menurut Romberg dalam Sutrisno (2009) seorang pegawai memiliki kompetensi yang tinggi apabila pegawai tersebut memiliki pengalaman kerja, latar belakang pendidikan yang mendukung profesi, memiliki keahlian/pengetahuan dan memiliki keterampilan.

\section{Pengaruh pengalaman kerja dengan kinerja pegawai}

Adanya hubungan pengalaman kerja dengan kinerja pegawai juga didukung oleh pendapat dari Robbins dan Timothy (2008:162) menyatakan bahwa: "Bahwa pengalaman kerja adalah tingkat penguasaan pengetahuan dan keterampilan seseorang dalam bekerja yang tampaknya menjadi sebuah dasar perkiraan yang baik atas kinerja pegawai”. Menurut Manulang (1994:15), pengalaman kerja adalah peroses pembentukan pengatahuan atau keterampilan tentang metode suatu pekerjaan kerena keterlibatan karyawan tersebut dalam pelaksanaan tugas dan pekerjaan.

\section{Pengaruh manajemen pengetahuan dengan motivasi}

Robbin (2002:55) mengemukakan bahwa motivasi adalah keinginan untuk melakukan sebagai kesediaan untuk mengeluarkan tingkat upaya yang tinggi untuk tujuan-tujuan organisasi, yang dikondisikan oleh kemampuan upaya itu untuk memenuhi suatu kebutuhan individual.

\section{Pengaruh kompetensi dengan motivasi}

Kompetensi dengan motivasi harus dijalankan bersama-sama agar bisa tetap berada di standar organisasi yang baik. Penelitian ini didukung peneliti yang dilakukan juga oleh (Ngatemin \& Arumwanti, 2013) yang dilakukan menyimpulkan bahwa kompetensi berpengaruh signifikan terhadap motivasi kerja.

\section{Pengaruh pengelaman kerja dengan motivasi}

pengertian Motivasi Suwanto dan Priansa (2011:171) mengatakan motivasi berasal dari kata latin movere yang berarti dorongan, daya penggerak atau kekuatan yang menyebabkan suatu tidakan atau perbuatan. Hasibuan (2006:143) mendefinisikan bahwa motivasi sebegai pemberian daya penggerak yang menciptakan kegairahan kerja seseorang agar mereka mau bekerja sama, bekerja efektif, dan terintegrasi dengan segala daya upaya untuk mencapai kepuasan.

\section{Pengaruh motivasi dengan kinerja pegawai}

Mullins (Kiruja, E. K., 2013), menyatakan bahwa memotivasi karyawan secara efektif adalah salah satu fungsi yang paling penting dari seorang manajer.Ada bukti yang menunjukkan bahwa organisasi yang menghadapi tantangan dalam mempertahankan karyawan karena peluang yangterbatas untuk kemajuan organisasidan pasar tenaga kerja yang kompetitif saat ini.

\section{Kerangka Pemikiran dan Hipotesis}


Nawawi (2015) melakukan penelitian dengan tujuan menganalisa hubungan antara job satisfaction dan motivasi terhadap employee performance terhadap karyawan outsourcing yang ditempatkan di Kampus II Universitas Tarumanagara, Jakarta. Dari penelitian ini dapat dibuktikan bahwa terdapat hubungan yang positif antara job satisfaction dengan employee performance.

Ridha choirun dkk juga berpendapat bahwa knowledge management adalah serangkaian proses penciptaan, pengkomunikasian, dan penerapan knowledge perusahaan sebagai pembelajaran untuk meningkatkan kinerja karyawan maupun organisasi. Hasil penelitian yang dilakukan oleh Ainanur dan satria Tirtayasa menyatakan bahwa Hasil pengujian hipotesis (H2) telah membuktikan terdapat pengaruh antara kompetensi terhadap kinerja pegawai. Hasil pengujian hipotesis (H3) telah membuktikan terdapat pengaruh antara motivasi terhadap kinerja pegawai. Hasil ini mendukung penelitian sebelumnya Oleh Gultom (2014) dengan judul Pengaruh Budaya Organisasi Perusahaan dan Motivasi Terhadap Kinerja Karyawan pada PT. Perusahaan Gas Negara (Persero) Tbk Medan dengan hasil analisis yaitu motivasi mempunyai pengaruh positif dan signifikan terhadap kinerja karyawan. berikut ini:

Dengan beberapa hasil penelitian diatas maka dapat digambarkan model penelitan seperti

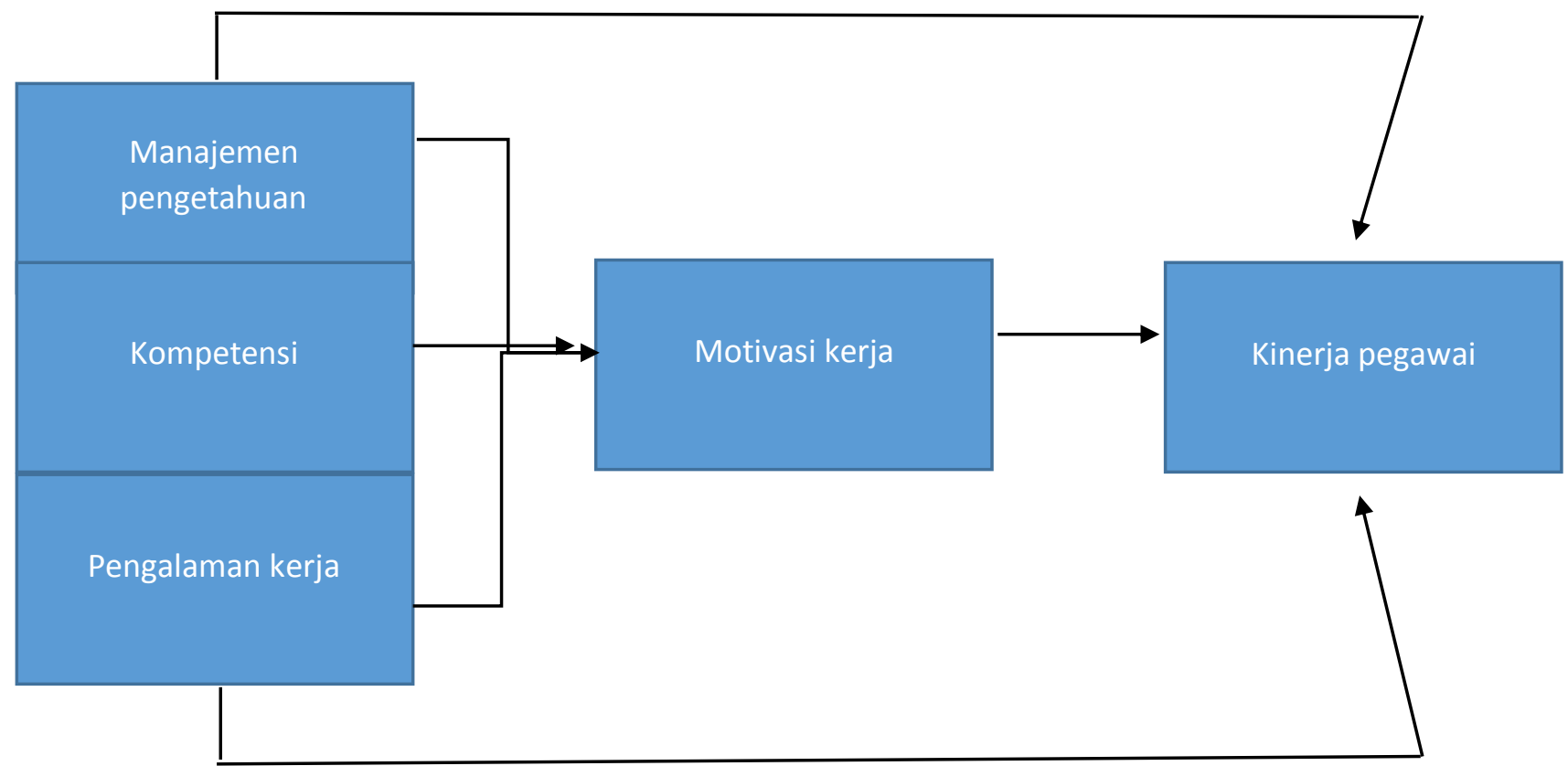

Berdasarkan kerangka pemikiran diatas maka akan dirumuskan hipotesis seperti dibawah ini:

H1: Terdapat pengaruh positif manajemen pengetahuan terhadap kinerja pegawai di Jakarta Utara.

$\mathrm{H} 2$ : Terdapat pengaruh positif kompetensi terhadap kinerja pegawai di Jakarta Utara.

H3: Terdapat pengaruh positif pengalaman kerja terhadap kinerja pegawai di Jakarta Utara.

H4: Terdapat pengaruh positif manajemen pengetahuan terhadap motivasi kerja di Jakarta Utara. 
H5: Terdapat pengaruh positif kompetensi terhadap motivasi kerja di Jakarta Utara.

H6: Terdapat pengaruh positif pengalaman kerja terhadap motivasi kerja di Jakarta Utara.

H7: Terdapat pengaruh positif motivasi kerja terhadap kinerja pegawai di Jakarta Utara.

\section{METODE PENELITIAN}

Menurut Sugiyono Pengertian metode penelitian adalah cara ilmiah untuk mendapatkan data dengan tujuan dapat dideskripsikan, dibuktikan, dikembangkan dan ditemukan pengetahuan, teori, untuk memahami, memecahkan, dan mengantisipasi masalah dalam kehidupan manusia (Sugiyono: 2012). Jenis penelitian yang digunakan merupakan penelitian deskriptif( Kuantitatif), dimana para variabel akan diukur berdasarkan skala Likert Teknik sampel yang akan digunakan dalam penelitian ini merupakan Non-Probability sample yaitu dimana pengambilan atau pemilihan sample tidak didasarkan pada hukum probabilitas dan tidak adanya peluang yang sama bagi anggota untuk tetap dipilih, dalam Non-Probability sampling terdapat beberapa macam seperti, purposive sampling, quota sampling, accidental sampling, dan snowball sampling. Disini peneliti akan menggunakan purposive sampling dikarenakan peneliti telah menemukan informasi yang memadai terakait penelitian sehingga dengan menggunakan teknik sampling ini akan membantu peneliti untuk mendapatkan sample yang baik dan benar. Metode pengumpulan data yang digunakan dalam penelitian dengan menggunakan kuesioner dan juga observasi, kuisioner digunakan karena lebih dapat menghemat waktu dan juga memiliki jangka waktu yang tidak lama. Menurut Widayat dan Amirullah (2008) definisi operasional variabel merupakan suatu definisi yang diungkapkan secara jelas dari masing-masing variabel dalam penelitian dan dijabarkan dalam indicator-indikator.

\section{HASIL DAN PEMBAHASAN}

\section{Hasil analisis Validitas}

Hasil AVE variabel, AVE dari setiap variabel telah lulus dan valid atau bisa dibilang telah memenuhi kriteria. Sehingga dapat disimpulkan bahwa penelitian ini telah lolos dalam pengujian convergent validity. nilai cross loading juga telah memenuhi kriteria yang dijelaskan yaitu nilai dari masing-masing variabelnya sendiri lebih besar dibandingkan dengan variabel lainya dalam penelitian ini. Sehingga seluruh variabel yang ada pada penelitian ini telah lulus atau valid dalam pengujian cross loadings. Berdasarkan perhitungan data dari fornell-larcker bisa kita simpulkan bahwa seluruh indicator telah memenuhi kriteria dari fornell-larcker walaupun masih ada beberapa variabel yang tidak melebihi dari variabel sebelumnya namun di variabel akhir merupakan hasil paling tinggi sehinga itu akan mempengaruhi seluruh variabel. Dan seluruh variabel dinyatakan lulus atau lolos pengujian convergent and construct validity maupun discriminant validity dan telah siap dilakukan uji boostrapping.

Hasil Average Variance Extracted (AVE)

\begin{tabular}{|c|c|}
\hline & AVE(Average Variance Extracted) \\
\hline Manajemen pengetahuan & 0.578 \\
\hline
\end{tabular}




\begin{tabular}{|c|c|}
\hline Kompetensi & 0.634 \\
\hline Pengalaman Kerja & 0.655 \\
\hline Motivasi Kerja & 0.519 \\
\hline Kinerja Pegawai & 0.702 \\
\hline
\end{tabular}

Dapat kita lihat pada Tabel 3.2 didapatkan hasil AVE variabel, AVE dari setiap variabel telah lulus dan valid atau bisa dibilang telah memenuhi kriteria. Sehingga dapat disimpulkan bahwa penelitian ini telah lolos dalam pengujian convergent validity.

\section{Hasil analisis Reliabilitas}

Hasil uji reliabilitas menunjukan bahwa seluruh variabel Manajemen Pengetahuan, Kompetensi, Pengalaman Kerja, Motivasi Kerja dan juga Kinerja Pegawai dapat dikatakan reliabel karena composite reliabilitynya sudah melewati kriteria yaitu 0.7 sehingga dapat dikategorikan sebagai varaibel yang valid. Ghozali (2018:45) menyatakan reliabilitas adalah alat untuk mengukur suatu kuesioner yang merupakan indikator dari variabel atau konstruk.

\begin{tabular}{|c|c|c|}
\hline Variabel & Composite Reliability & Croncbach's Alpha \\
\hline Manajemen Pengetahuan & 0.804 & 0.631 \\
\hline Kompetensi & 0.776 & 0.422 \\
\hline Pengalaman Kerja & 0.790 & 0.488 \\
\hline Motivasi Kerja & 0.761 & 0.544 \\
\hline Kinerja Pegawai & 0.823 & 0.603 \\
\hline
\end{tabular}

\section{Koefisien Determinasi $\left(\mathbf{R}^{2}\right)$}

Berdasarkan hasil uji data koefisien determinasi bawah variabel dependen kinerja pegawai 0.399 yang berarti 39,9\% variabel dependen dapat dijelaskan oleh variabel independen seperti manajemen pengetahuan, kompetensi, pengelaman kerja. Sisanya sebesar $71.1 \%$ dapat dijelaskan oleh variabel lainya yang tidak diteliti dalam penelitian ini. Selanjutnya, pada tabel 4.13 terlihat data nilai $R$-square untuk motivasi kerja nilainya 0.456 yang berarti $45,6 \%$ variabel intervening ini dapat dimengerti oleh variabel lainya yang ada di dalam penelitian ini dan sisanya sebesar $55,4 \%$ dapat dijelaskan oleh variabel lain yang tidak ada dalam penelitian ini. Berdasarkan hasil dari $R$-square diatas dapat disimpulkan nilai koefisien ini tergolong lemah dan moderate yaitu 0,399 dan juga 0,456 . 
Tabel 4.13

Hasil Data Koefisien Determinasi $\left(\mathbf{R}^{2}\right)$

\begin{tabular}{|c|c|}
\hline Variabel & R-Square \\
\hline Kinerja Pegawai & 0.399 \\
\hline Motivasi Kerja & 0.456 \\
\hline
\end{tabular}

$\mathrm{H}_{1}=$ Terdapat pengaruh positif manajemen pengetahuan terhadap kinerja pegawai di Jakarta utara.

Hasil pengujian hipotesis yang telah dilakukan pada tabel 4.17 dapat disimpulkan bahwa variabel manajemen pengetahuan berpengaruh secara positif terhadap kinerja pegawai di Jakarta Utara karena hal ini dapat dilihat dari nilai t-statistic dan p-values yang telah diuji pada tabel 4.17, dimana nilai $t$-statistic pada variabel manajemen pengetahuan sebesar 2.585 dimana nilai ini sudah melewati nilai minimal yaitu 1.96 dan nilai $p$-values sebesar 0.005 dimana nilai ini juga sudah melewati batas minimal yaitu 0.000 , maka dapat disimpulkan $\mathrm{H}_{1}$ pada penelitian ini tidak ditolak atau diterima.

\section{$\mathrm{H}_{2}=$ Terdapat pengaruh positif kompetensi terhadap kinerja pegawai di Jakarta utara.}

Hasil pengujian hipotesis yang telah dilakukan pada tabel 4.17 dapat disimpulkan bahwa variabel Kompetensi berpengaruh secara positif terhadap kinerja pegawai di Jakarta utara, hal ini disebabkan nilai $t$-statistic pada variabel kompetensi sebesar 1,842 dan nilai $p$-values sebesar 0.033 dimana kedua nilai tersebut sudah melewati nilai minimal yaitu 1.96 dan 0.000 walaupun pada $t$ statistic terlihat kurang namun di p-values sudah memenuhi. Maka dapat disimpulkan $\mathrm{H}_{2}$ pada penelitian ini tidak ditolak atau diterima

\section{$\mathrm{H}_{3}=$ Terdapat pengaruh positif pengalaman kerja terhadap kinerja pegawai di Jakarta utara.}

Hasil pengujian hipotesis yang telah dilakukan pada tabel boostrapping 4.17 dapat disimpulkan bahwa variabel pengalaman kerja tidak berpengaruh secara positif terhadap kinerja pegawai di Jakarta utara, hal ini disebabkan nilai $t$-statistic dan nilai $p$-values yang tidak memenuhi syarat dari uji hipotesis yaitu senilai 0.903 dan 0.183 , yang dimana harusnya nilai $t$-statistic harus bisa melewati atau mendekati 1.96. maka kita simpulkan $\mathrm{H}_{3}$ ditolak dan tidak berpengaruh positif terhadap kinerja pegawai.

$\mathrm{H}_{4}=$ Terdapat pengaruh positif manajemen pengetahuan terhadap motivasi kerja di Jakarta utara.

Pada pengujian hipotesis yang telah dilakukan oleh peneliti pada tabel boostrapping 4.17, kita dapat melihat bahwa variabel manajemen pengetahuan berpengaruh secara positif terhadap motivasi kerja di Jakarta utara, hal ini bisa terjadi karena nilai pada $t$-statistic dan $p$-values yang sudah melewati kriteria, nilai tersebut adalah 2.080 dan 0.019 dimana nilai $t$-statistic sudah melewati 1.96 dan p-values melewati 0.00, maka secara tidak langsung bisa kita simpulkan uji hipotesis keempat diterima atau tidak ditolak. 


\section{$H_{5}=$ Terdapat pengaruh positif kompetensi terhadap motivasi kerja di Jakarta utara.}

Pengujian hipotesis pada tabel boostrapping 4.16 kali ini bisa kita lihat bahwa variabel kompetensi berpengaruh secara positif terhadap motivasi kerja di Jakarta utara. Hal ini disebabkan karena nilai $t$-statistic yang sebesar 2.202 telah melewati 1.96 (kriteria) dan nilai $p$-values senilai 0.014 yang dimana harus melewati 0.000 . maka dari itu bisa disimpulkan bahwa $\mathrm{H}_{5}$ bisa diterima atau tidak ditolak

\section{$H_{6}=$ Terdapat pengaruh positif pengalaman kerja terhadap motivasi kerja di Jakarta utara .}

Hasil dari uji hipotesis pada tabel 4.17 menjelaskan bahwa variabel pengalaman kerja berpengaruh secara positif terhadap motivasi kerja di daerah Jakarta utara. Hal ini disebabkan karena adanya nilai $t$-statistic yaitu 2.267 sudah melewati kriteria senilai 1.96 dan juga nilai $p$ values yang sebesar 0,012 sudah melewati kriteria senilai 0.000, maka dari itu bisa disimpulkan bahwa $\mathrm{H}_{6}$ diterima atau tidak ditolak.

\section{$\mathrm{H}_{7}=$ Terdapat pengaruh positif motivasi kerja terhadap kinerja pegawai di Jakarta utara.}

Hasil dari uji hipotesis ini sedikit berbeda dari kelima hipotesis lainya karena pada variabel ini Motivasi kerja tidak berpengaruh secara positif terhadap kinerja pegawai, hal ini dapat terjadi karena kurangnya nilai $t$-statistic dan juga $p$-values yang sebesar 0.756 dan 0.225 dimana nilai ini tidak melewati kriteria yaitu 1.96 dan 0.000 , maka dari itu dapat kita simpulkan bahwa $\mathrm{H}_{7}$ ditolak atau tidak diterima.

\section{KESIMPULAN}

Berdasarkan pada hasil yang telah diuji, maka hasil penelitian dapat disimpulkan sebagai berikut:

1. Manajemen pengetahuan berpengaruh positif terhadap kinerja pegawai di Jakarta utara.

2. Kompetensi berpengaruh positif terhadap Kinerja pegawai di Jakarta utara.

3. Pengalaman kerja tidak berpengaruh positif terhadap Kinerja pegawai di Jakarta utara.

4. Manajemen pengetahuan berpengaruh positif terhadap Motivasi kerja di Jakarta utara.

5. Kompetensi berpengaruh positif terhadap Motivasi kerja di Jakarta utara.

6. Pengalaman kerja berpengaruh positif terhadap Motivasi kerja di Jakarta utara.

7. Motivasi kerja tidak berpengaruh positif terhadap Kinerja pegawai di Jakarta utara.

\section{SARAN}

a) Saran dari peneliti ialah agar para perusahaan dan peneliti selanjutnya dapat memperhatikan indicator-indicator yang lemah pada penelitian ini yaitu dalam variabel manajemen pengetahuan yang tergolong lemah adalah knowledge application dan juga knowledge protection, lalu dalam variabel kompetensi ada indicator merumuskan, menyusun dan juga mengestimasi, pada variabel pengalaman kerja terdapat indicator yang harus diperhatikan juga karena tergolong lemah yaitu lamanya bekerja, dan lainya. Perusahaan harus memperhatikan masalah kecil seperti ini agar dapat meningkatkan kinerja para pegawainya dikarenakan indicator kecil ini dapat membuat dampak yang besar bagi perusahaan.

b) Untuk penelitian selanjutnya saya sarankan agar penelitian selanjutnya dapat menjangkau daerah atau cluster yang lebih luas lagi tidak hanya di Jakarta utara sehingga penelitian 
yang akan dilakukan dapat lebih maximal dan tidak memiliki keterbatasan yang tidak dinginkan dimana ini dapat menjadi informasi bagi seluruh perusahaan di Jakarta utara maupun sekitarnya.

\section{DAFTAR PUSTAKA}

Ainanur, \& Tirtayasa, S. (2018). Pengaruh Budaya Organisasi, Kompetensi Dan Motivasi Terhadap Kinerja Karyawan, Vol 1(No. 1), 1-14. https://doi.org/Maneggio: Jurnal Ilmiah Magister Manajemen

Avera, S. K., \& Nawawi, T. (2019). Pengaruh Budaya Organisasi Dan Kepuasan Kerja Terhadap Kinerja Karyawan Dan Komitmen Organisasi Sebagai Variabel Mediasi Pada PT Tiki Jalur Nugraha Ekakurir Jakarta, Volume I (No. 4), 811-819.

Bili, W., Resmawan, E., \& Kondorura, D. (2018). Pengaruh pengalaman kerja terhadap kinerja pegawai di kantor kecamatan laham kabupaten Mahakam Ulu, 6(3), 465-474.

Budiaji, W. (n.d.). Skala pengukuran dan jumlah respon skala Likert (The Measurement Scale and The Number of Responses in Likert Scale).

Dermawan, N. B. (2012). Pengaruh motivasi, lingkungan kerja, kompetensi, dan kompensasi terhadap kepuasan kerja dan kinerja pegawai di lingkungan kantor dinas pekerjaan umum provinsi Bali, 6(No 2).

Fadhil, A., \& Mayowan, Y. (2018). Pengaruh motivasi kerja dan kepuasan kerja terhadap kinerja karyawan AJB Bumiputera, VOL 54 (NO 1).

Fifi Surya Dewi Kusuma, \& Home, D. (2013). Analisa Pengaruh Knowledge Management Terhadap Keunggulan Bersaing Dan Kinerja Perusahaan, Vol 1(No 2).

Hanafi, B. D. (2017). Pengaruh motivasi, dan lingkungan kerja, terhadap kinerja karyawan, dengan kepuasan kerja sebagai variabel mediasi pada PT Bnilifein Surance, Vol 5 (No 1). https://doi.org/JPEB

Harmen, H., \& Darma, M. T. (n.d.). Pengaruh Talent Management Dan Knowledge Management Terhadap Kinerja Karyawan PT. Perkebunan Nusantara II (Survei Pada Kantor Direksi Tanjung Morawa), Vol. 4 (2)). https://doi.org/Jurnal Konsep Bisnis dan Manajemen

Hidayat, A. (2018). PLS SEM: Pengukuran Kecocokan Model (Inner Dan Outer) .

Hidayat, A. (n.d.). Populasi dan Sampel: Pengertian Populasi Adalah? https://www.statistikian.com/2012/10/pengertian-populasi-dansampel.html\#Pengertian_Populasi_Menurut_Ahli_Sugiyono_Bugin_dan_Nursalam.

Kartika, L. N., \& Sugiarto, A. (2014). Pengaruh tingkat kompetensi terhadap kinerja pegawai administrasi perkantoran, Volume XVII (No. 1).

Laporan Perkembangan Ekonomi Indonesia dan Dunia Triwulan I Tahun 2020. (n.d.). https://www.bappenas.go.id/id/berita-dan-siaran-pers/laporan-perkembangan-ekonomiindonesia-dan-dunia-triwulan-i-tahun-2020/. Linda, M. R., Megawati, \& Japriska, Y. (2014). Analisis pengaruh beban kerja, lingkungan kerja, dan motivasi kerja terhadap kinerja pegawai dan kepegawaian daerah kabupaten pesisir selatan dengan menggunakan partial least square (PLS, Volume 3(Nomor 1). https://doi.org/Jurnal Kajian Manajemen Bisnis

Luh Aristarini, I Ketut Kirya, \& Yulianthini, N. N. (2014). Pengaruh pengalaman kerja, kompetensi social dan motivasi kerja terhadap kinerja karyawan pada bagian pemasaran 
PT Adira Finance Singaraja, 2. https://doi.org/e-Journal Bisma Universitas Pendidikan Ganesha Jurusan Manajemen

Meidita, A. (2019). Pengaruh Pelatihan Dan Kompetensi Terhadap Kepuasan Kerja Melalui Motivasi Kerja, Vol 2(No. 2), 226-237.

Mohamad, R., \& Nawawi, M. T. (2020). Pengaruh Organizational Learning, Organizational Commitment Dan Job Satisfaction Terhadap Employee Performance Di Jakarta, Volume II (No. 4), 1060-1069. 